\title{
296 In the oesophagus
}

A The pharynx joins it at the glossoepiglottic folds.

B There are only 2 constrictions along its length.

C The non-striated muscle has a motor supply from the vagus.

D Portal-systemic anastamoses are located in the middle third.

E The cricopharyngeal sphincter is about $3 \mathrm{~cm}$ in length.

\section{The lower oesophageal sphincter}

A Can be demonstrated histologically.

B A pinch cock effect is produced by the left crus of the diaphragm.

C May be merely mucosal folds in the lower end of the oesophagus.

D A normal oesophagogastric angle prevents acid reflux.

E The sling of Willis is essential in sphincteric action.

\section{Congenital oesophageal atresia}

A Over $80 \%$ of cases are associated with a tracheo-oesophageal fistula.

B Gas in the gastro-intestinal tract implies the presence of polyhydramnios.

C Feeding may produce aspiration pneumonitis.

D After successful surgical correction swallowing develops normally.

E Mortality is related to the site of the defect. 